\title{
Education and Behavioural Barriers for Menstrual Health Communication between Parent and Adolescent Girls
}

\author{
Suma K G \\ Department of Social Work, Vijaynagar Srikrishna Devaray University, \\ P G Center Nandihalli, \\ Sandur, Karnataka, India
}

\begin{abstract}
This study is an empirical attempt to understand parental communication about bleeding, first period and dysmenorrhea with adolescent girls. It examines the barriers of communication from the adolescent girls' perspective. The study was conducted in a couple of taluks of ballari district, i.e., Sandur and Hospet. In order to achieve the objectives of the study, a descriptive research design was adopted. The data was gathered using the interview schedule from 260 adolescent girls adopting a random sampling method. The findings of the study reveal that the mean age of the adolescent girls was 15.34 years. It was found that the parents' behaviour and educational level impact communication with adolescent girls with reference to bleeding, first period and dysmenorrhea. The Chi-Square test has been done to assess the relationship between communicational barriers and education. The ANOVA test has been applied to understand the relationship between parents' behaviour, educational level and communication barriers.
\end{abstract}

Keywords: Communication, Menstrual Health, Bleeding, Parent-Adolescent

\section{Introduction}

Menstruation may be a rhythmical alignment or an attunement to numerous internal and external cycles for many women. The experience's variety is connected to a woman's psychological, physiological, and behavioral reactions to her periods.

The hormonal changes that occur during a woman's menstrual cycle can have an impact on many parts of her life, including her mood, conduct, and overall well-being. These variations are referred to as biopsychosocial fluctuations (Golub \& Harrington, 1981).

Menstruation influences about 2 billion women and girls worldwide monthly. Despite this, millions of women are denied the right to dignified and healthy period management. Many teenage girls experience social isolation during their periods due to various issues such as gender inequity, insufficient hygienic facilities, and cultural taboos. (UNICEF 2019).

Many variables can have an impact on a child's health during puberty. These include the possibility of becoming pregnant too soon, having a bad marriage, or experiencing psychiatric issues. The fast 
changes that occur throughout puberty can also result in a variety of issues, such as infections and injuries (Azh, 2017).

Since adolescence is a time when young people are prone to various health-related concerns, they must have access to trustworthy information about puberty and other health-related subjects. The mainstream media, books and programmes, and female-centered education are the three primary sources of knowledge about puberty (Gultie et al., 2014).

Menstrual disorders are frequent issues in late adolescence; teenage girls suffer from some form of menstrual disorder. These include delayed, abnormal, painful, and excessive menstrual flow, which are the most prevalent causes of concern among teenagers (Bulto, 2021).

Communication between parents and their kids is crucial. However, it can be hard for parents to communicate effectively due to the nature of the issues involved. Communication between parents and adolescent girls is one of the most critical components of parenting. Parenting is difficult when it comes to communicating with their children about menstrual health management.

The interactions between parents and their kids can affect the development of both their health and welfare. A study revealed that the role of mothers in shaping one's child's life is important to preventing stress and obstacles from happening to her (Blum et al., 2012).

Parents are the primary educators of their children. Most parents feel that their adolescent children should receive sexual-reproductive health education. Notably, research indicates that youngsters should discuss their sexual health with their parents. There are several advantages for parents and their children speaking about sexual and reproductive health since teenagers can gain information about menstrual health management practices. Many studies have shown that sexual health communication has a significant impact on postponing first sexual experiences, lowering sexual desire, boosting contraception and condom usage, and decreasing the number of sexual partners. Positive impressions of communication between adolescents and their parents are clearly associated with healthier and safer menstrual health practices (Lefkowitz, 2002).

Through their conversations with their daughters, mothers can provide vital information about reproductive health and improve the quality of their relationships. However, they should also be aware of the various factors that can prevent them from imparting their information effectively (Katherine Hutchinson et al., 2012).

The lack of mothers' awareness about the school's role in puberty discussions was another barrier to the proper participation of mothers and daughters. One of the factors that prevented the mothers from communicating with their daughters about puberty was their busy schedule. This is because they are responsible for the care of other children.

Since childhood, most adolescent girls have been taught about sex and abstinence-only by their grandmother or aunt. However, this practice is not uncommon among parents, who often use religious instruction instead of direct communication with their adolescent girls. 


\section{Objectives of the Study}

1. To understand the knowledge barriers to parent-adolescent communication about bleeding, first period, and dysmenorrhea.

2. To identify the behavioral barriers to parent-adolescent communication about bleeding, first period, and dysmenorrhea.

\section{Methodology of Research}

To achieve its objectives, the present study adopted a descriptive research design. The universe of the study comprises all the adolescent girls aged 14 to 17 in the Ballari district of Karnataka. A semi-structured interview schedule was developed and standardized to collect primary data. Indepth interviews, observation, and focus group discussion techniques were used. The data collected was subjected to processing. The processed data is entered into a computer. With the help of the Statistical Package for Social Science, descriptive and inferential data analysis were conducted. Focus group discussion results are presented in support of quantitative data.

\section{Data Analysis and Discussion}

With reference to the socio-demographic details (Table 1) of the respondents, the average age of the respondents is 15.34, indicating that all respondents are in late adolescence. The mean age of physical maturity is 12.52 . It is also worth noting that most respondents are second children to their parents, with a mean score of 2.39 .

Table 1: Socio-demographic Data of the Adolescents

\begin{tabular}{|l|c|c|c|}
\hline Variables & Range & Mean & Variance \\
\hline Age of the adolescent girls & 3 & 15.34 & 1.292 \\
\hline Age at physical maturity & 3 & 12.52 & 0.621 \\
\hline Birth order & 3 & 2.20 & 0.848 \\
\hline Number of siblings & 3 & 2.39 & 1.003 \\
\hline
\end{tabular}

Table 2: Knowledge and Behavioral Barriers for Communication

\begin{tabular}{|l|l|c|c|c|c|c|c|c|c|c|}
\hline \multirow{2}{*}{$\begin{array}{l}\text { Sr. } \\
\text { No. }\end{array}$} & \multirow{3}{*}{ Barriers for Communication } & \multicolumn{3}{|c|}{ Bleeding } & \multicolumn{3}{c|}{ First Period } & \multicolumn{3}{c|}{$\begin{array}{c}\text { Dysmenorrhea } \\
\text { (Pain during Menstruation) }\end{array}$} \\
\cline { 2 - 11 } & $\Psi$ & df & SL & $\Psi$ & df & SL & $\Psi$ & df & SL \\
\hline 1 & $\begin{array}{l}\text { Inadequate communication } \\
\text { skills }\end{array}$ & $264.855^{\mathrm{a}}$ & 12 & .000 & $261.258^{\mathrm{a}}$ & 12 & .000 & $260.877^{\mathrm{a}}$ & 12 & .000 \\
\hline 2 & $\begin{array}{l}\text { Parents' lack of knowledge of } \\
\text { RSH }\end{array}$ & $260.331^{\mathrm{a}}$ & 10 & .000 & $260.815^{\mathrm{a}}$ & 10 & .000 & $263.877^{\mathrm{a}}$ & 10 & .000 \\
\hline 3 & $\begin{array}{l}\text { Parent's low educational } \\
\text { attainment }\end{array}$ & $263.045^{\mathrm{a}}$ & 8 & .000 & $260.765^{\mathrm{a}}$ & 8 & .000 & $262.190^{\mathrm{a}}$ & 8 & .000 \\
\hline 4 & Feeling of embarrassment & $260.340^{\mathrm{a}}$ & 8 & .000 & $260.247^{\mathrm{a}}$ & 8 & .000 & $260.597^{\mathrm{a}}$ & 10 & .000 \\
\hline 5 & Parents are not interested & $261.699^{\mathrm{a}}$ & 8 & .000 & $260.304^{\mathrm{a}}$ & 8 & .000 & $260.221^{\mathrm{a}}$ & 8 & .000 \\
\hline 6 & Parents hesitant & $262.230^{\mathrm{a}}$ & 10 & .000 & $262.105^{\mathrm{a}}$ & 10 & .000 & $260.106^{\mathrm{a}}$ & 8 & .000 \\
\hline 7 & Stigmatization feeling & $264.608^{\mathrm{a}}$ & 10 & .000 & $261.610^{\mathrm{a}}$ & 10 & .000 & $261.435^{\mathrm{a}}$ & 12 & .000 \\
\hline 8 & I feel a generation state gap & $262.105^{\mathrm{a}}$ & 12 & .000 & $261.810^{\mathrm{a}}$ & 12 & .000 & $262.925^{\mathrm{a}}$ & 10 & .000 \\
\hline
\end{tabular}




\begin{tabular}{|l|l|l|l|l|l|l|l|l|l|l|}
\hline & between my parents and me & & & & & & & & & \\
\hline 9 & Strictness behavior of parents & $265.064^{\mathrm{a}}$ & 12 & .000 & $263.687^{\mathrm{a}}$ & 12 & .000 & $263.412^{\mathrm{a}}$ & 12 & .000 \\
\hline 10 & Rough and tough demeanor & $262.511^{\mathrm{a}}$ & 10 & .000 & $261.407^{\mathrm{a}}$ & 10 & .000 & $260.762^{\mathrm{a}}$ & 10 & .000 \\
\hline
\end{tabular}

Parents' expertise is arguably the essential aspect to consider; it is critical to provide teenage girls with information on bleeding, their first period, and dysmenorrhea throughout the menstrual cycle. The chi-square test is used to determine whether there is a relationship between parents' knowledge and behavioral barriers for communicating about bleeding, first period, and dysmenorrhea. Significantly, it is discovered that there is a relationship between parents' knowledge, education, understanding, attitudes, and behaviour when communicating about bleeding, first period, and dysmenorrhea. To dispel myths, concerns, and misconceptions about menstruation health and management among teenage girls, it is necessary for parents to gain knowledge of the subject.

Although many parents support the importance of having informed and guided discussions about menstrual health activities with their kids, many of them are reluctant to talk about reproductive health with their kids due to their cultural and social backgrounds.

Since adolescent girls typically receive sex education from their mothers, they are not likely to discuss menstrual health and reproductive health topics with their parents. This is because traditional religious beliefs and norms prevent parents from discussing these issues with their kids.

Not having good knowledge about puberty can create barriers to communication, which is in line with the present study. These findings also support the notion that parents should not discuss these issues with their daughters so as to prevent the delivery of incorrect information and the shame and embarrassment it can cause.

Having good overall knowledge about adolescent reproductive health issues such as puberty was associated with a higher likelihood of reducing communication barriers. This finding is consistent with the findings of a study.

The present study revealed that most of the respondents were not interested in discussing menstrual health issues. The quantitative results of this study are also supported by qualitative data that states: many hurdles exist between parents and adolescent girls, according to the focus group findings. These include a lack of communication skills, a lack of understanding about menstrual health and reproductive health, parental reluctance, and family conflict. Although many parents encountered difficulties, many still attempted to talk to their adolescent daughters about menstrual and reproductive health.

While Shalini and Madhavi (names changed) showed that their parents were well-educated and aware of such concerns, they could not communicate effectively with one another regarding reproductive and menstrual health. There are times when people are too conservative, such as Madhavi's parents, and would avoid discussion despite speaking with them frequently. 


\section{Suggestions}

As a result of the findings, the following suggestions are made.

- There is a need to arm and educate parents about various SRH concerns through the use of relevant IEC materials and communication skills linked to menstrual and reproductive health.

- It is critical to encourage and enable parents to initiate menstrual health communication with their children when they are still in late childhood or early adolescence.

- Additionally, parents must be empowered and encouraged to provide healthy role models and advice to both male and female adolescent children.

- Comprehensive family-life-education (FLE) must be implemented in schools, homes, churches, mosques, and health facilities for students and parents.

- Adolescents should be introduced to effective sex education at a young age, preferably in school.

- Additional research should be performed to determine the factors that contribute to the initiation, quality, and timing of parent-adolescent communication about menstrual health issues.

\section{Conclusions}

The environment of the family plays a huge role in the development of the adolescent girl. It is therefore important that parents and adolescent girls are able to communicate about menstrual health issues in a proper manner. Appropriate, and adequate information about menstrual health is critical for adolescent girls' overall development. In this regard, parents in general, and mothers in particular, play a critical role. Mothers of same-gender can make a significant difference in the lives of adolescent females. There are various communication hurdles that influence the family, parents, and young females as well. Overcoming all of these obstacles contributes to adolescent females' self-development. It is not only assisting a girl but also assisting a future mother.

\section{References}

1. Azh N. (2017) Adolescents Confusion in Receiving Health Services: A Qualitative Study. Journal of Clinical and Diagnostic Research. DOI: 10.7860/jcdr/2017/23393.9761

2. Blum R. W., Bastos F. I. P. M., Kabiru C. W., Le L. C. (2012) Adolescent health in the 21 st century. Lancet (London, England). 379 (9826). 1567-1568. DOI: 10.1016/S01406736(12)60407-3

3. Bulto G. A. (2021) Knowledge on Menstruation and Practice of Menstrual Hygiene Management Among School Adolescent Girls in Central Ethiopia: A Cross-Sectional Study. Risk Management and Healthcare Policy. Volume 14. 911-923. DOI: $\underline{10.2147 / \mathrm{rmhp} . \mathrm{s} 296670}$

4. Golub S., Harrington D. M. (1981) Premenstrual and menstrual mood changes in adolescent women. Journal of Personality and Social Psychology. 41 (5). 961-965. DOI: 10.1037/0022$\underline{3514.41 .5 .961}$

5. Gultie T., Hailu D., Workineh Y. (2014) Age of Menarche and Knowledge about Menstrual Hygiene Management among Adolescent School Girls in Amhara Province, Ethiopia: Implication to Health Care Workers \& School Teachers. PLoS ONE. 9 (9). e108644. 10.1371/journal.pone.0108644

6. Katherine Hutchinson M., Kahwa E., Waldron N., Hepburn Brown C., Hamilton P. I., Hewitt H. H., Aiken J., Cederbaum J., Alter E., Sweet Jemmott L. (2012) Jamaican Mothers' 
Influences of Adolescent Girls' Sexual Beliefs and Behaviors. Journal of Nursing Scholarship. 44 (1). 27-35. DOI: 10.1111/j.1547-5069.2011.01431.x

7. Lefkowitz E. S. (2002) Beyond the yes-no question: Measuring parent-adolescent communication about sex. New Directions for Child and Adolescent Development. 2002 (97). 43-56. DOI: $\underline{10.1002 / \mathrm{cd} .49}$

8. UNICEF. (2019) Guidance on Menstrual Health and Hygiene. https://www.unicef.org/media/91341/file/UNICEF-Guidance-menstrual-health-hygiene2019.pdf 